\title{
Genetic diagnosis and pathogenic analysis of an atypical hereditary spherocytosis combined with UGT1A1 partial deficiency: A case report
}

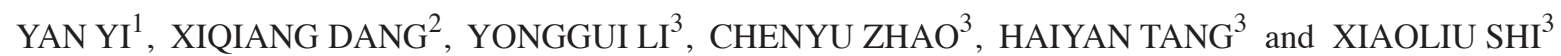 \\ Departments of ${ }^{1}$ Haematology, ${ }^{2}$ Pediatrics and ${ }^{3}$ Medical Genetics, The Second Xiangya Hospital of \\ Central South University, Changsha, Hunan 410011, P.R. China
}

Received April 17, 2017; Accepted August 31, 2017

DOI: $10.3892 / \mathrm{mmr} .2017 .7867$

\begin{abstract}
Patients with combined hereditary spherocytosis (HS) and uridine diphosphate glucuronosyltransferase 1A1 (UGT1A1) deficiency have been reported sporadically. A discrepancy between the level of elevated serum bilirubin concentration and the degree of anemia may suggest the possibility of a coexistence of these conditions. In the present case report, a 20-year-old female presented with congenital jaundice and anemia, but did not present with the discrepancy between hyperbilirubinemia and anemia in the patient's childhood, and was not previously diagnosed with either HS or UGT1A1 deficiency. During a follow-up of $>10$ years, the patient's hyperbilirubinemia accumulated progressively, whereas the patient's anemia became relatively mild. Upon further genetic analysis, it was determined that the patient had HS combined with UGT1A1 partial deficiency. Next generation sequencing combined with direct sequencing was used to identify a novel heterozygous mutation (c.G828T; p.Y276X) in the spectrin $\beta$ gene, which is causative for HS. Sequence analysis of the patients' UGT1A1 gene revealed a compound heterozygote with c.G211A (p.G71R) and T3279G mutations, which reduced UGT1A1 activity to $30-60 \%$ of the normal level. Genetic analysis was crucial for determining the diagnosis and pathogenesis of this unusual case.
\end{abstract}

\section{Introduction}

Hereditary spherocytosis (HS) and uridine diphosphate glucuronosyltransferase 1A1 (UGT1A1) deficiency are common inherited conditions characterized by unconjugated

Correspondence to: Professor Xiaoliu Shi, Department of Medical Genetics, The Second Xiangya Hospital of Central South University, 139 Middle Renmin Road, Changsha, Hunan 410011, P.R. China E-mail: shix16@csu.edu.cn

Key words: hereditary spherocytosis, uridine diphosphate glucuronosyltransferase 1A1, genetic diagnosis, pathogenesis, next generation sequencing, spectrin $\beta$ gene hyperbilirubinemia. HS is an inherited hemolytic anemia caused by constitutional erythrocyte membrane defects, and characterized clinically by anemia with variable severity, jaundice and splenomegaly (1). Diagnosis is usually established based on the presence of spherocytes, increased erythrocyte osmotic fragility and the absence of any other cause of the hemolytic anemia (1). UGT1A1 is responsible for bilirubin glucuronidation, and reduced activity of UGT1A1 is associated with an increased level of unconjugated bilirubin (2). UGT1A1 deficiency is a common hereditary condition of bilirubin metabolism in the general population, particularly in Asian communities $(2,3)$.

As the prevalence of HS is 1 in 2,000 (4), and that of UGT1A1 caused by G211A mutation deficiency is much higher at $13-23 \%$ in Asian newborns $(2,3)$, diagnoses of their coexistence should not be rare; however, the number of documented cases is low $(5,6)$. This underdiagnosis may be attributed to one condition masking another (7), or to a lack of conclusive evidence for their coexistence. In the present case report, atypical HS combined with UGT1A1 partial deficiency was diagnosed by pathogenic gene analysis. A novel c.G828T (Y276X) mutation in spectrin $\beta(S P T B)$, which is causative for HS, along with compound heterozygous mutations in UGT1A1, T3279G and G211A, which are pathogenic for UGT1A1 partial deficiency, were identified. In addition, the individual pathogenesis of hyperbilirubinemia was investigated for this patient.

\section{Materials and methods}

Patient. The present study was approved by the Ethics Committee of the Second Xiangya Hospital of Central South University (Changsha, China), and written informed consent was obtained from the patient and the patient's mother. On July 12, 2016, a 20-year-old female with congenital jaundice and anemia for $\sim 20$ years was re-hospitalized to confirm the patient's condition. The proband was diagnosed with neonatal jaundice several days following birth. In 2003, when the patient was 7 years old, splenomegaly, anemia and jaundice were detected. Between 2004 and 2005, hyperplastic anemia (hemoglobin, $96 \mathrm{~g} / \mathrm{l}$; reticulocytes, 0.05), splenomegaly, elevated serum bilirubin [total bilirubin (TBIL), $36.9 \mu \mathrm{mol} / \mathrm{l}$; 
direct bilirubin, $11.3 \mu \mathrm{mol} / \mathrm{l}]$ and detectable spherocytes in blood smear were identified, and HS was suspected. However, the erythrocyte osmotic fragility test, which is a crucial test for HS diagnosis, was repeatedly normal. Furthermore, the elevated serum bilirubin concentration decreased to normal level following phenobarbitone treatment, which suggested UGT1A1 deficiency, which would not contribute to hyperplastic anemia and splenomegaly. Subsequently, the patient has been interviewed regularly. Upon infection or overexertion, the patient's serum bilirubin increased significantly, mainly by unconjugated bilirubin. Notably, bilirubin levels gradually increased over time, whereas the anemia was mild. In 2013, when the patient was 17 years old, the patient's serum TBIL rose to $>80 \mu \mathrm{mol} / 1$ and hemoglobin was $>100 \mathrm{~g} / 1$. There was no history of alcoholism, hepatitis, drug ingestion or drug abuse. The proband's father had a history of cholelithiasis, and succumbed to cirrhosis in his twenties. The patient's father's brother also died early, and presented with jaundice at his death.

Clinical analysis. The proband received a detailed clinical evaluation at the Second Xiangya Hospital of Central South University. Extensive laboratory testing was performed, including complete blood count, liver functional tests, lactate dehydrogenase, vitamin B12, folate, iron studies, rheumatoid factor and anti-nuclear antibodies testing, erythrocyte osmotic fragility test, hemoglobin electrophoresis, Ham test, glucose-6-phasphate dehydrogenase activity, Coombs' direct and indirect tests, flow cytometric test using eosin-5'-maleimide (EMA) labeling of red blood cells $(1,8)$ as well as abdominal computed tomography (CT) scans. Additionally, bone marrow and blood smears of the patients were stained by Wright-Giemsa staining for $30 \mathrm{~min}$ at room temperature. Then the smears were observed using a light microscope, erythrocyte morphology was evaluated, and the proportion of spherocytes was counted among 500 erythrocytes.

Genetic analysis. A total of $5 \mathrm{ml}$ peripheral vein blood was drawn from the proband and the proband's mother. The genomic DNA was extracted using QIAamp DNA Blood Mini kit (cat. no. 51104; Qiagen GmbH, Hilden, Germany) according to the manufacturer's protocol, quantified using an Eppendorf BioPhotometer ${ }^{\circledR}$ D30 (Eppendorf, Hamburg, Germany) and stored at $-20^{\circ} \mathrm{C}$ until use. Then the genomic DNA library was constructed according to the Agilent's protocol for Preparing Samples for Sequencing Genomic DNA. Using the SureSelectXT Reagent kits (cat. no. G9611B; Agilent Technologies, Inc., Santa Clara, CA, USA), $3 \mu \mathrm{g}$ high-quality gDNA was sheared by the Bioruptor ${ }^{\circledR}$ Plus sonication device (Diagenode S.A., Seraing, Belgium) with 175 peak incident power, end-repaired at $20^{\circ} \mathrm{C}(30 \mathrm{~min})$, adenylated at $37^{\circ} \mathrm{C}(30 \mathrm{~min})$ and ligated with an adaptor at $20^{\circ} \mathrm{C}(15 \mathrm{~min})$ using a next-generation high throughout sequencer (HiSeq 2000 v3; Illumina, Inc., San Diego, CA, USA). The DNA fragments were purified at each step with AMPure XP beads DNA Purification kit (cat. no. A63880; Beckman Coulter, Inc., Brea, CA, USA) according to the manufacturer's protocol.

The 5 known genes associated with inherited spherocytosis include ankyrin $1, S P T B$, spectrin $\alpha$ erythrocytic 11 , solute carrier family 4 member 1 and erythrocyte membrane protein band 4.2 gene. To amplify and capture the 5 known genes a costumed Agilent Comparative Genomic Hybridization Array for the exons and adjacent intron regions (50 bp) of the 5 genes and SureSelect Focused Exome kit (cat. no. 5190-7788, Agilent Technologies, Inc.) were used according to the manufacturer's protocol. The adaptor-ligated library was amplified in $25 \mu \mathrm{l}$ reaction using 5X Herculase II Reaction Buffer $(5 \mu \mathrm{l})$, SureSelect Primer and SureSelect ILM Indexing Pre-Capture PCR Reverse Primer (0.625 $\mu \mathrm{l}$ each), $100 \mathrm{mM}$ dNTP mix $(0.25 \mu \mathrm{l})$, Herculase II Fusion DNA Polymerase $(0.5 \mu \mathrm{l})$ and adaptor-ligated DNA $(18 \mu \mathrm{l})$. The thermal cycler conditions were as follows: Initial denaturation at $98^{\circ} \mathrm{C}$ for $2 \mathrm{~min}$, 4-6 cycles of denaturation at $98^{\circ} \mathrm{C}(30 \mathrm{sec})$, annealing at $65^{\circ} \mathrm{C}$ $(30 \mathrm{sec})$ and extension at $72^{\circ} \mathrm{C}(1 \mathrm{~min})$, and final extension at $72^{\circ} \mathrm{C}(10 \mathrm{~min})$.

To capture the target DNA fragments, $500 \mathrm{ng}$ total library, which was concentrated by a vacuum concentrator (Concentrator Plus; Eppendorf), was hybridized with streptavidin-coated beads, at $65^{\circ} \mathrm{C}$ for $24 \mathrm{~h}$. Then the captured gene fragments were sequenced by the next-generation high throughput sequencer. The results demonstrated that $88.61 \%$ of target bases were covered to a total depth of $>20 \mathrm{X}$ with high quality (Q20) reads. Reads were aligned to the reference sequence University of California Santa Cruz, human genome assembly 19 (UCSC.hg19; genome.ucsc.edu/). Variants, including single-nucleotide polymorphisms (SNPs) and indels, were identified and called with the VCFtools program of the SAMTools software, version 0.1.16 (samtools. sourceforge.net/). Amino acid substitutions that affected protein function were annotated with polymorphism phenotyping v2 (PolyPhen-2; genetics.bwh.harvard.edu/pph2) and MutationTaster2 (mutationtaster.org). Pathogenicity of the variants was interpreted according to the American College of Medical Genetics (ACMG) guidelines (9).

The detected mutation in SPTB was confirmed by direct sequencing of the polymerase chain reaction (PCR) products amplified from the genomic DNA samples of the patient and her mother, which were extracted from their blood as mentioned above. Genome DNA samples were amplified in $25 \mu \mathrm{l}$ reactions using 2X Power Taq PCR MasterMix (12.5 $\mu \mathrm{l}$; BioTeke Corporation, Beijing, China), nuclease-free water (11 $\mu \mathrm{l}), 10 \mathrm{pmol} / \mu \mathrm{l}$ forward and reverse primers $(0.5 \mu \mathrm{l}$ each), and $100 \mathrm{ng} / \mu \mathrm{l}$ template $(0.5 \mu \mathrm{l})$. The thermocycling conditions were as follows: Initial denaturation at $95^{\circ} \mathrm{C}$ for $3 \mathrm{~min}$, 30 cycles of denaturation at $95^{\circ} \mathrm{C}(30 \mathrm{sec})$, annealing at $57^{\circ} \mathrm{C}$ (30 sec) and extension at $72^{\circ} \mathrm{C}(1 \mathrm{~min})$, and final extension at $72^{\circ} \mathrm{C}$ (7 min). Primers for PCR were designed using primer3 software (primer3.ut.ee): SPTB forward, 5'-TGCTCTGTT GGTTGTCACTTG-3' and reverse, 5'-AGCCATCAATGT TGCCAAGG-3'. PCR products were examined on $1 \%$ agarose gels containing $0.5 \mu \mathrm{g} / \mathrm{ml}$ ethidium bromide and were subsequently sequenced on an ABI 3730 DNA Analyzer (Applied Biosystems; Thermo Fisher Scientific, Inc., Waltham, MA, USA). Sequence comparisons and analysis were performed using Phred-Phrap-Consed version 12.0 software (phrap. org/phredphrapconsed.html). Sequencing results were compared with the reference sequence for SPTB (GenBank accession no. NM_001024858) in the UCSC database to confirm potential mutation. Then the detected mutation in 
Table I. Primers sequences of uridine diphosphate glucuronosyltransferase 1Al gene.

\begin{tabular}{|c|c|c|c|}
\hline UGTIAl exon & Primer sequence $\left(5^{\prime} \rightarrow 3^{\prime}\right)$ & Amplicon size (bp) & Annealing temperature $\left({ }^{\circ} \mathrm{C}\right)$ \\
\hline Exon 1-1 & $\begin{array}{l}\text { F: TATAAGTAGGAGAGGGCGAACC } \\
\text { R: TCAAATTCCAGGCTGCATG }\end{array}$ & 588 & 57 \\
\hline Exon 1-2 & $\begin{array}{l}\text { F: GGCCTCCCTGGCAGAAAG } \\
\text { R: ATGCCAAAGACAGACTCAAACC }\end{array}$ & 617 & 60 \\
\hline Exon 2 & $\begin{array}{l}\text { F: AGGAACCCTTCCTCCTTTAGA } \\
\text { R: GAAGCTGGAAGTCTGGGATTAG }\end{array}$ & 402 & 59 \\
\hline Exon 3 & $\begin{array}{l}\text { F: CCTCAGAAGCCTTCACAGTTAC } \\
\text { R: ATCCAATCCGCCCAACATAC }\end{array}$ & 255 & 59 \\
\hline Exon 4 & $\begin{array}{l}\text { F: GTGTCCAGCTGTGAAACTCA } \\
\text { R: TGAATGCCATGACCAAAGTATTC }\end{array}$ & 323 & 55 \\
\hline Exon 5 & $\begin{array}{l}\text { F: CAACAGGGCAAGACTCTGTATC } \\
\text { R: CCTTATTTCCCACCCACTTCTC }\end{array}$ & 489 & 60 \\
\hline Promoter & $\begin{array}{l}\text { F: ACAGGTTTCCATGGCGAAAG } \\
\text { R: TGTTTTGATCACACGCTGCA }\end{array}$ & 782 & 56 \\
\hline PBREM & $\begin{array}{l}\text { F: GGTCACTCAATTCCAAGGGG } \\
\text { R: GCATCCAAGCCAGCAAGTAA }\end{array}$ & 598 & 61 \\
\hline
\end{tabular}

PBREM, phenobarbital responsive enhancer module; UGT1A1, uridine diphosphate glucuronosyltransferase 1A1; F, forward; R, reverse; bp, base pairs.

SPTB (G828T) was absent in the 1,000 Genomes Project database and Exome Aggregation (10).

Amplification of the exons, the promoter region and the enhancer region [that is, the phenobarbital responsive enhancer module (PBREM)] of UGTIAl was performed by PCR. Genome DNA samples were amplified in reactions as mentioned above. Thermocycling conditions were as follows: Initial denaturation at $95^{\circ} \mathrm{C}$ for $3 \mathrm{~min}, 30$ cycles of denaturation at $95^{\circ} \mathrm{C}(30 \mathrm{sec})$, annealing temperatures as shown in Table I (30 sec), extension at $72^{\circ} \mathrm{C}(1 \mathrm{~min})$, and final extension at $72^{\circ} \mathrm{C}$ (7 min). Primer sequences are listed in Table I. Amplified DNA fragments were sequenced as aforementioned. Mutations in UGTIAl were identified by comparing the sequencing results with the reported reference sequence (GenBank accession no. NM_000463).

\section{Results}

Clinical diagnosis. Physical examination revealed cutaneous and icteric sclera; spleen was palpable $4 \mathrm{~cm}$ below costal margin, and was firm and non-tender. TBIL was $106.2 \mu \mathrm{mol} / 1$ and direct bilirubin was $7.5 \mu \mathrm{mol} / 1$. The complete blood count revealed hemoglobin $103 \mathrm{~g} / 1$, reticulocytes $0.358 \times 10^{12} / 1$, mean corpuscular volume $84.3 \mathrm{fl}$, mean corpuscular hemoglobin $30.6 \mathrm{pg}$ and mean corpuscular hemoglobin concentration $363 \mathrm{~g} / \mathrm{l}$, and white blood cell and platelet counts were normal.

Extensive laboratory evaluation revealed normal levels of alanine aminotransferase, aspartate transaminase, lactate dehydrogenase, vitamin B12, folate, iron studies, rheumatoid factor and anti-nuclear antibodies. A series of diagnostic tests for hemolytic anemia, including erythrocyte osmotic fragility test, hemoglobin electrophoresis, Ham's test, glucose-6-phosphate dehydrogenase activity, Coombs' direct and indirect tests were normal. Bone marrow smear indicated hypercellular

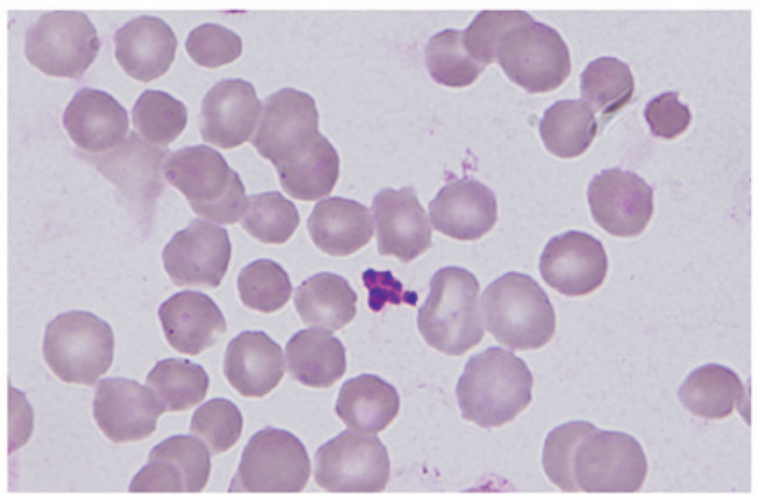

Figure 1. Peripheral blood smear from the patient. Some red cells presented with dense, spheroidal shape using the Wright-Giemsa stain, whereas other cells retained a central concavity. Magnification, $\mathrm{x} 400$.

marrow with myeloid-to-erythroid precursor ratio of 0.4:1. Blood smear results demonstrated that spherocytes accounted for 62 out of 500 red blood cells (Fig. 1). EMA test of red blood for the diagnosis of HS was positive. An abdominal CT scan revealed splenomegaly without the combination of gallstone or cholangiectasis.

HS was diagnosed clinically based on the presence of hyperplastic anemia, splenomegaly and spherocytes, and particularly, the positive EMA test. Although the erythrocyte osmotic fragility test was repeatedly normal, the positive EMA test supported the diagnosis of HS.

Pathogenic mutation analysis of SPTB. Sequencing analysis revealed that the proband was heterozygous for the c.G828T (p.Y276X) mutation within exon 7 of SPTB, which was not present in the mother (Fig. 2). This mutation introduced a premature stop codon at amino acid residue 276 , which created 

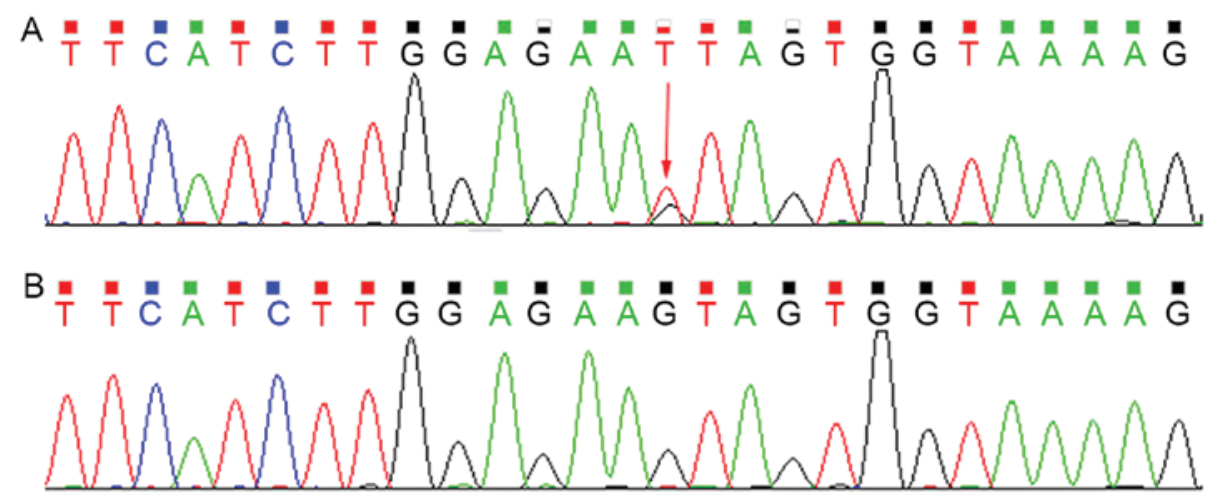

Figure 2. Nonsense mutation of c.G828T (p.Y276X) within exon 7 of the spectrin $\beta$ gene. The sequencing results of (A) the patient (mutant) and (B) the patient's mother (wild-type). The red arrow indicates the mutation.

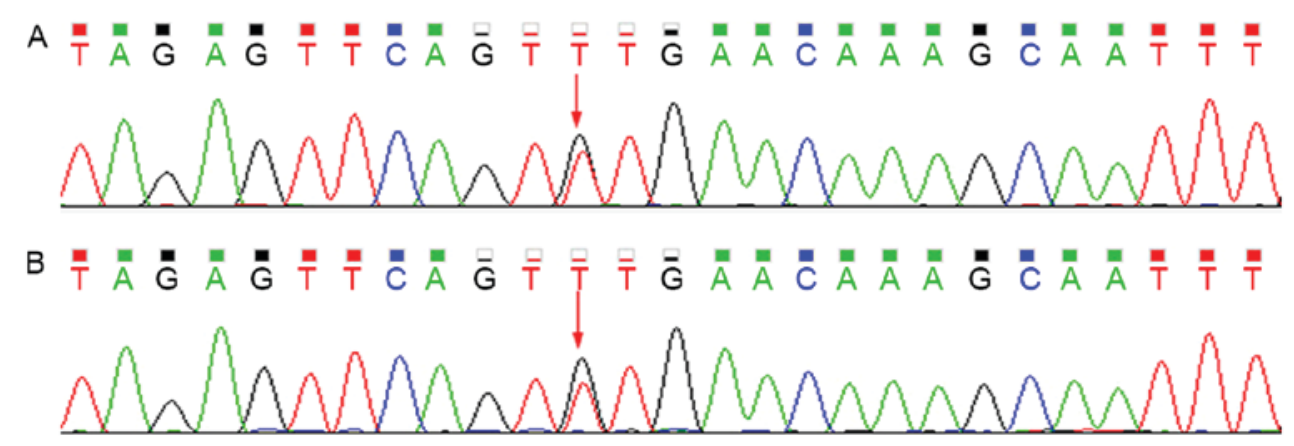

Figure 3. Heterozygous mutation c.T3279G within the phenobarbital-responsive enhancer module of the uridine diphosphate glucuronosyltransferase 1A1 gene. Sequencing results of (A) the patient and (B) the patient's mother, suggested that the c.T3279G in the patient may have been inherited from the patient's mother. The red arrow indicates the mutation.

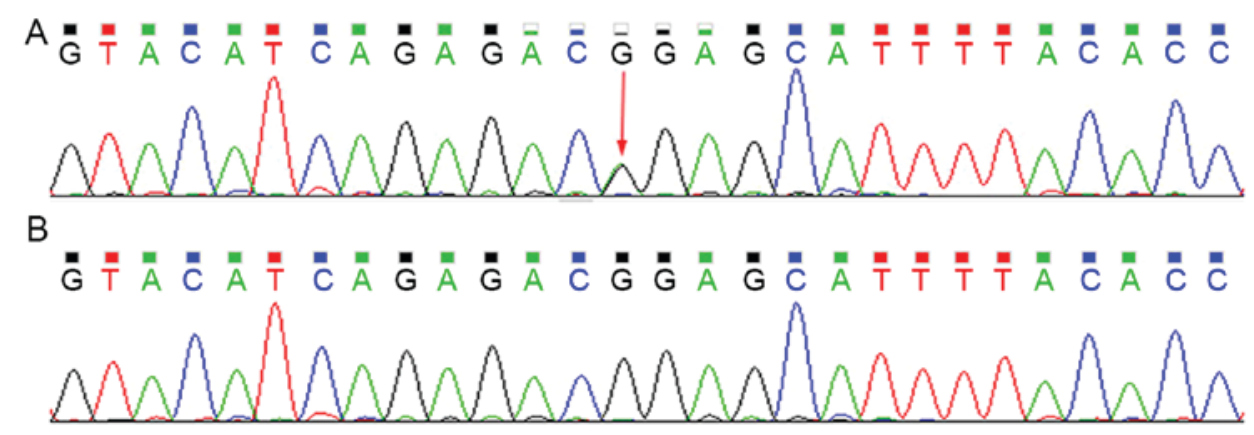

Figure 4. Missense mutation of c.G211A (p.G71R) within exon 1 of the uridine diphosphate glucuronosyltransferase $1 \mathrm{~A} 1$ gene. The sequencing results of (A) the patient (mutant) and (B) the patient's mother (wild-type). The red arrow indicates the mutation.

a truncated protein and was predicted to be disease-causing by the analytical software used. In addition, it had not been reported previously and is a novel mutation.

Although SPTB c.G828T may be a novel mutation, several nonsense mutations located downstream of it have been previously identified as pathogenic mutations $(11,12)$. Therefore, combined with the patient's clinical diagnosis of HS, the c.G828T SNP was identified as a pathogenic mutation, and was probably causative for this HS development in this patient, according to the ACMG guidelines. Notably, although previously reported cases of HS that had nonsense mutations in SPTB displayed a conspicuous spherocytosis with frequently encountered dense spiculated red blood cells (11), the spherocytes of the present case had not exhibited prominent surface projections (Fig. 1).
Pathogenic mutation analysis of UGT1A1. Sequencing analysis revealed that the patient harbored the c.G211A (p.G71R) heterozygous mutation within exon 1 of UGT1A1 and the T3279G heterozygous mutation within the PBREM of UGT1A1. The heterozygous T3279G mutation was also detected in the proband's mother, whereas the G211A mutation was not (Figs. 3 and 4).

In a previous study, the heterozygous G211A mutation was reported to reduce UGT1A1 transferase activity to $60 \%$ of the normal level, and the homozygous G211A mutation reduced the activity to $30 \%$, whereas the homozygous T3279G mutation reduced the activity to approximately $60 \%$ (13). Therefore, the compound heterozygous mutations may result in 30-60\% activity of the normal UGT1A1 level. 

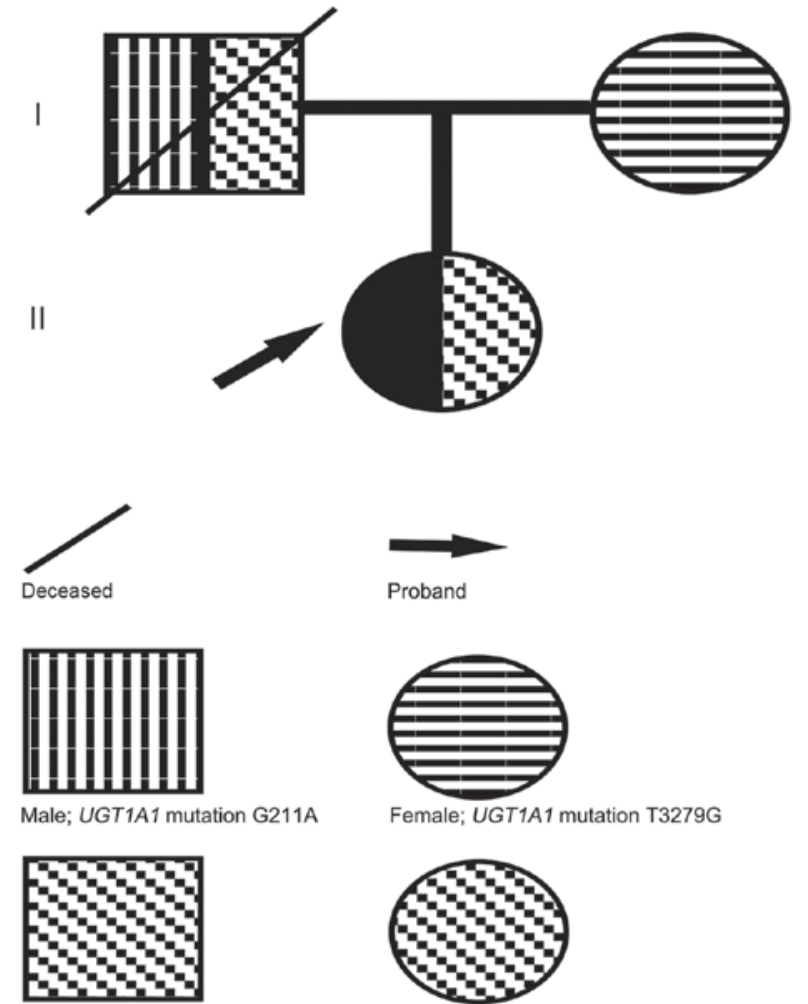

Male; SPTB mutation G828T

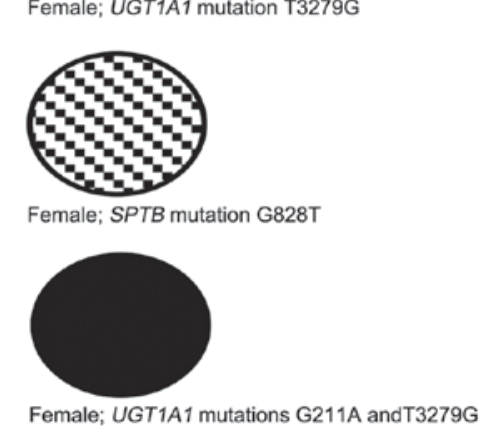

Figure 5. Pedigree of the case study patient's family with hereditary spherocytosis and $U G T 1 A 1$ deficiency. $S P T B$, spectrin $\beta ; U G T 1 A 1$, uridine diphosphate glucuronosyltransferase $1 \mathrm{~A} 1$.

Based on the present results, UGT1A1 partial deficiency was diagnosed.

\section{Discussion}

HS and UGT1A1 deficiency are relatively common causes of unconjugated hyperbilirubinemia, and their coexistence may interfere with the proper diagnosis (2-4). The present study described a female Chinese patient presenting with congenital jaundice and anemia that was eventually diagnosed as having HS combined with UGT1A1 deficiency following follow-up of $>10$ years.

In the present case, anemia, splenomegaly, reticulocytosis, spherocytes, hypercellular bone marrow with remarkable erythroid hyperplasia and positive family history had led to the presumptive diagnosis of HS. However, the erythrocyte osmotic fragility test was repeatedly normal, and there was no cut-off value of spherocytes for the diagnosis of HS. Therefore, confirmation of the diagnosis relied on the positive EMA test and genetic analysis.

As the patient's clinical findings were not typical for both HS and UGT1A1 deficiency, the diagnoses had been pending for $>10$ years. Notably, the serum bilirubin levels increased over time; while the patient's anemia became milder. Then, up to puberty, the discrepancy in the severity of hyperbilirubinemia and anemia became significant, which may be related to the increased hemoglobin turnover around puberty (5). This discrepancy suggests that the patient's HS coexists with other conditions associated with unconjugated hyperbilirubinemia, especially UGT1A1 partial deficiency. Therefore, for patients with similar discrepancies (inappropriately high serum bilirubin level compared with the degree of hemolysis), the possibility of the coexistence of UGT1A1 partial deficiency and HS should be considered.

HS is normally inherited in an autosomal dominant manner, which may be induced by pathogenic mutations in ankyrin 1 on chromosome 8p11, SPTB on chromosome 14q23, spectrin $\alpha$ erythrocytic 1 on chromosome 1q21, solute carrier family 4 member 1 on chromosome 17q21, or erythrocyte membrane protein band 4.2 on chromosome $15 q 15$ (14). As HS may develop from multiple pathogenic genes, genetic diagnosis was not applicable prior to the clinical application of NGS. In previously reported cases of HS combined with UGT1A1 deficiency, the diagnosis of HS was based on typical clinical findings, such as spherocytes with increased erythrocyte osmotic fragility $(5,6)$. Thus, atypical cases with normal erythrocyte osmotic fragility may have been underdiagnosed. The present study used NGS combined with direct sequencing to identify a novel pathogenic mutation, SPTB G828T, and the diagnosis of HS was confirmed in this case study. The SPTB G828T mutation was not present in the proband's mother, and was probably inherited from the deceased father (Fig. 5).

UGT1A1 deficiency results from the causative mutations in UGT1Al gene, which is located on chromosome 2q37 (15). A number mutations or SNPs of UGT1A1 that influence bilirubin glucuronidation have been identified, which may cause Crigler-Najjar syndrome, Gilbert's syndrome, neonatal hyperbilirubinemia or non-symptom based on the severity of the decrease in enzymatic activity $(16,17)$. Therefore, genetic analysis was crucial to clarify the diagnosis and severity of UGT1A1 deficiency. In the present case report, compound heterozygous mutations (T3279G and G211A) probably led to the reduced UGT1A1 activity, to $30-60 \%$ of normal activity; patients with 30-60\% UGT1A1 activity are typically asymptomatic (13), other than experiencing jaundice if not in combination with other conditions such as HS. The T3279G mutation of UGTIAl in the proband was also detected in the mother, but the G211A mutation was not, which suggested that the patient inherited the $\mathrm{T} 3279 \mathrm{G}$ mutation from the patient's mother and the G211A mutation from the patient's deceased father (Fig. 5). Additionally, although the proband did not develop gallstones, which is common in patients with both HS and UGT1A1 deficiency (18), the patient was considered to be at-risk for cholelithiasis and was advised to accept periodical abdominal ultrasonic examination.

In conclusion, both HS and UGT1A1 deficiency are associated with hyperbilirubinemia, and their coexistence is often underdiagnosed. The discrepancy between the level of elevated serum bilirubin and the degree of hemolysis suggested the possibility of the coexistence. However, when the clinical or laboratory findings were inconclusive, the diagnosis was questioned; thus, genetic analysis was crucial to confirm the diagnosis and to avoid underdiagnosis. Early diagnosis saves time-consuming clinical reasoning and observation. Comprehensive NGS, as a new diagnostic tool, may 
not only identify HS specifically and efficiently, but also may contribute to expanding the mutation spectrum of associated genes. In addition, genetic analysis combined with evaluation of UGT1A1 activity may clarify the pathogenesis of the associated hyperbilirubinemia and may explain the clinical variability, which may aid patients in making informed medical and personal decisions.

\section{Acknowledgements}

The present study was supported in part by the National Natural Sciences Foundation of China (grant no. 81100360).

\section{References}

1. Bolton-Maggs PH, Langer JC, Iolascon A, Tittensor P and King MJ; General Haematology Task Force of the British Committee for Standards in Haematology: Guidelines for the diagnosis and management of hereditary spherocytosis-2011 update. Br J Haematol 156: 37-49, 2012.

2. Udomuksorn W, Elliot DJ, Lewis BC, Machenzie PI, Yoovathaworn $\mathrm{K}$ and Miners JO: Influence of mutations associated with Gilbert and Crigler-Najjar type II syndromes on the glucuronidation kinetics of bilirubin and other UDP-glucuronosyltransferase 1A substrates. Pharmacogenet Genomics 17: 1017-1029, 2007.

3. Akaba K, Kimura T, Sasaki A, Tanabe S, Ikegami T, Hashimoto M, Umeda H, Yoshida H, Umetsu K, Chiba H, et al: Neonatal hyperbilirubinemia and mutation of the bilirubin uridine diphosphate-glucuronosyltransferase gene: A common missense mutation among Japanese, Koreans and Chinese. Biochem Mol Biol Int 46: 21-26, 1998.

4. Tse WT and Lux SE: Red blood cell membrane disorders. Br J Haematol 104: 2-13, 1999.

5. Garg PK, Kumar A, Teckchandani N and Hadke NS: Hereditary spherocytosis coexisting with Gilbert's syndrome: A diagnostic dilemma. Singapore Med J 49: e308-e309, 2008.

6. Iijima S, Ohzeki T and Maruo Y: Hereditary spherocytosis coexisting with UDP-glucuronosyltransferase deficiency highly suggestive of Crigler-Najjar syndrome type II. Yonsei Med J 52: 369-372, 2011.

7. Sharma S, Vukelja SJ and Kadakia S: Gilbert's syndrome co-existing with and masking hereditary spherocytosis. Ann Hematol 74: 287-289, 1997.
8. Girodon F, Garçon L, Bergoin E, Largier M, Delaunay J, Fénéant-Thibault M, Maynadié M, Couillaud G, Moreira S and CynoberT: Usefulness of the eosin-5'-maleimide cytometric method as a first-line screening test for the diagnosis of hereditary spherocytosis: Comparison with ektacytometry and protein electrophoresis. Br J Haematol 140: 468-470, 2008.

9. Richards S, Aziz N, Bale S, Bick D, Das S, Gastier-Foster J, Grody WW, Hegde M, Lyon E, Spector E, et al: Standards and guidelines for the interpretation of sequence variants: A joint consensus recommendation of the American college of medical genetics and genomics and the association for molecular pathology. Genet Med 17: 405-424, 2015.

10. 1000 Genomes Project Consortium, Abecasis GR, Altshuler D, Auton A, Brooks LD, Durbin RM, Gibbs RA, Hurles ME and McVean GA: A map of human genome variation from population-scale sequencing. Nature 467: 1061-1073, 2010.

11. Hassoun H, Vassiliadis JN, Murray J, Njolstad PR, Rogus JJ, Ballas SK, Schaffer F, Jarolim P, Brabec V and Palek J: Characterization of the underlying molecular defect in hereditary spherocytosis associated with spectrin deficiency. Blood 90: 398-406, 1997.

12. Maciag M,Płochocka D, Adamowicz-Salach A and Burzyńska B: Novel beta-spectrin mutations in hereditary spherocytosis associated with decreased levels of mRNA. Br J Haematol 146: 326-332, 2009.

13. Sugatani J, Yamakawa K, Yoshinari K, Machida T, Takagi H, Mori M, Kakizaki S, Sueyoshi T, Negishi M and Miwa M: Identification of a defect in the UGT1A1 gene promoter and its association with hyperbilirubinemia. Biochem Biophys Res Commun 292: 492-497, 2002.

14. Delaunay J, Alloisio N, Morle L, Baklouti F, Dalla Venezia N, Maillet P and Wilmotte R: Molecular genetics of hereditary elliptocytosis and hereditary spherocytosis. Ann Genet 39: 209-221, 1996.

15. van Es HH, Bout A, Liu J, Anderson L, Duncan AM, Bosma P, Oude Elferink R, Jansen PL, Chowdhury JR and Schurr E: Assignment of the human UDP glucuronosyltransferase gene (UGT1A1) to chromosome region 2q37. Cytogenet Cell Genet 63: 114-116, 1993.

16. Yu Z, Zhu K, Wang L, Liu Y and Sun J: Association of neonatal hyperbilirubinemia with UGT1A1 gene polymorphisms: A meta-analysis. Med Sci Monit 21: 3104-3114, 2015.

17. Yamamoto K, Sato H, Fujiyama Y, Doida Y and Bamba T: Contribution of two missense mutations (G71R and Y486D) of the bilirubin UDP glycosyltransferase (UGT1A1) gene to phenotypes of Gilbert's syndrome and Crigler-Najjar syndrome type II. Biochim Biophys Acta 1406: 267-273, 1998.

18. del Giudice EM, Perrotta S, Nobili B, Specchia C, d'Urzo G and Iolascon A: Coinheritance of Gilbert syndrome increases the risk for developing gallstones in patients with hereditary spherocytosis. Blood 94: 2259-2262, 1999. 